\title{
Mothers' Knowledge and Practice about Conjunctivitis in Early Childhood at Assiut Ophthalmology Hospital
}

\author{
Huda Sayed Mohammed, Hekmat Ibrahim Abd-El-Kreme \& Khalid Ibrahim El-sayh, \\ Nursing specialist at Abnub Secondary Nursing School, Egypt. \\ Assistant Professor of Pediatric Nursing, Faculty of Nursing, Assiut University, Egypt. \\ Assistant Professor of pediatric, Faculty of Medicine, Assiut University, Egypt.
}

\begin{abstract}
Conjunctivitis is an inflammation due to infection in the lining over the eyeball and inside the eyelids. Inflammation can cause blood vessels in the eye to become larger; this makes the white of the eye look pink or red. Conjunctivitis is common among children under five years of age. Aims: To assess mothers' knowledge and practice about conjunctivitis in early childhood ( $<5$ years) at Assuit Ophthalmology Hospital. Design: Descriptive research design was used. Setting: The study was conducted in outpatient clinic at Assuit Ophthalmology Hospital. The Subjects: subject consisted of 200 mothers having children at early childhood $(<5$ years $)$ and suffering from conjunctivitis. Results: Results revealed that more than two fifths of them aged $1-<3$ years. Female constituted $52.0 \%$ of the studied children. The majority of mothers lived in rural areas. The vast majority of them had poor knowledge and practice about conjunctivitis at Assuit Ophthalmology Hospital. Conclusions: There were significant relations between mothers' education, occupation, their knowledge and practice regarding early childhood conjunctivitis at Assuit Ophthalmology Hospital. Recommendation: Follow up sheet to every child has conjunctivitis frequently to identify causes of his recurrent infection and prevent it before complications that are avoidable before occurring.
\end{abstract}

\section{Keyword: Knowledge ,Practice, Mothers \& Early Childhood Conjunctivitis.}

\section{Introduction}

Conjunctivitis is an inflammation of the conjunctiva caused by an infection or other irritant. One type of conjunctivitis caused by a bacterium is acute contagious conjunctivitis, also called pinkeye. The conjunctiva is usually clear, but if irritation or infection occurs, the lining becomes red and swollen (Rod et al., 2011). Children are exposed to various epidemiological factors in the environment which influence their present and future state of health. Suffering from conjunctivitis is the most frequent episode in childhood experiences. A productive and energetic population cannot grow from unhealthy children who are chronically affected by repeated conjunctivitis. So eye diseases represent an important public health problem in childhood (Navachetan, 2011).

Conjunctivitis is one of the most common ocular problems seen in the community. Conjunctivitis is a common infection especially among children under five year. In children, bacterial conjunctivitis is more common than viral and is mainly caused by $\mathrm{H}$. influenza, S.pneumoniae and M.catarrhlis (Denniston, 2008, Brunner \& suddarth, 2008).

Outbreaks are occurring throughout the world. It usually responds quickly to the right treatment. Some areas of northern Egypt reported an outbreak of pinkeye with the number of cases close to 2000 (Centers for Disease Control \& Prevention (CDC), 2014).
The contagious type of pinkeye spreads quickly through a family and among children who spend time together at school, daycare, or other group events. It spreads easily from one eye to the other through contact with contaminated fingers that have rubbed the infected eye. It then spreads to others through direct contact with an infected person; such as using an infected towel (American Academy of Pediatrics, 2012).

Prevention of infective conjunctivitis relies primarily on good personal hygiene. Ophthalmia neonatorum for example can be prevented by the use of povidone iodine drops, tetracycline eye ointment or other antiseptics or antibiotics. (Sherwin et al., 2002). Treatment start by keeping children's eyes clean eyes should be washed gently several times a day with cotton wool soaked in tepid water. Appropriate antibiotic eye drops or ointment may be prescribed for several days. Topical antihistamines also could be administered if the child has allergic conjunctivitis (American Academy of Pediatrics, 2010)

Nursing management of the various types of conjunctivitis focuses on alleviating symptoms and preventing spread of infection. Ophthalmic nurses have an important role as teachers and advisors, in educating mothers care of their children ; in providing health education in society; and by facilitating the development of other multidisciplinary team members 'knowledge and 
understanding of conjunctivitis (Royal College of Nursing, 2009).

\section{Significance of the study}

Many Egyptian studies that revealed acute conjunctivitis as the most common eye disorder in young children. So this study will be conducted to educate mothers how to prevent and treat pediatric conjunctivitis. Mothers were taken as a sample to this study to educate them to provide good care to their children and because the children with conjunctivitis need for home care that carried out by their mothers and not need hospital admission to improve.

\section{Aim of the study}

The aim of this study is to assess mothers' knowledge and practice about conjunctivitis in early childhood ( $<5$ years) at Assuit Ophthalmology Hospital.

\section{Research questions}

1-Is there a relationship between mothers' knowledge, practice, and their personal characteristics?

2-Is there a relationship between mothers' knowledge and their practice

\section{Subjects and method}

\section{Research design}

Descriptive research design was used.

\section{Subjects}

Subject consisted of 200 mothers having children at early childhood (< 5 years) and suffering from conjunctivitis.

\section{Setting}

This study was conducted in outpatient clinic at Assuit Ophthalmology Hospital, Egypt.

\section{Material and methods}

\section{Tools of the study}

One tool was used for this study. A structured interview questioner sheet about mothers' knowledge and practice regarding conjunctivitis was developed by the researcher to collect the necessary data and composed of two parts as the following:

\section{- Part one: This part was related to}

1- Characteristics of mothers and their children

a) Mothers' characters such as (age, educational level, working condition, health condition, and marital status...etc).

b) Children's characters such as (age, sex, family size, birth order, health history, and residence area....etc).

2-Medical data of children suffering from conjunctivitis as (Redness of the eye, swelling and redness of the eyelids, burning sensation in eyes, tears, itching, purulent discharge \&watery discharge, adhesive eyelids at morning time duo to excessive secretions, photophobia ...etc)

\section{- Part two}

a) Mothers' knowledge about conjunctivitis such as (definition, causes, and symptoms, method of infection, complication, and treatment...etc). (7 questions; score of two for complete answer, score of one for correct but incomplete answer, score of zero for incorrect answer and I don't know). The score of each item summed-up and then converted into percent score where poor $=$ $>50 \%$, fair $=50-65 \%$, good $=<65 \%$.

b) Mothers' practice regarding care provided for children with conjunctivitis such as:

- Use of personal protective measurement to prevent spread of infection (10 questions)

- Mothers' practice to alleviate symptoms of conjunctivitis. (Go to hospital or pharmacies to get medication, rinse the eye several times a day with water, clean the eyelid margins and eyelashes gently and repeatedly with a warm, moist cloth or cotton ball, cold compresses to cases of allergy conjunctivitis, warm compress to cases of infectious conjunctivitis) Score of two for correct and complete practice, score of one for correct but incomplete practice, score of zero for incorrect or I don't know. The score of each item summed-up and then converted into percent score Poor practice $=$ $>50 \%$, fair practice $=50-65 \%$, good practice $=<$ $65 \%$.

\section{Preparatory phase}

Permission was obtained to collect data before starting this study, it was necessary to secure the approval of authorities in the setting of the study. Therefor an official permission was obtained from the dean of the faculty of nursing, Assuit University to the director of Assuit Ophthalmology Hospital. A review of the current and past available literature on the various aspects of the problem using textbooks, articles and magazines were done in order to give a clear picture about the research problem and to develop the study tools. This review was helpful in developing the tool used in the study. Tool was constructed by the researcher and revised by jury of experts in the field of the study.

- Validity of tool was estimated by 5 experts in pediatric field and its result was $95 \%$

- Reliability was estimated by Alpha Cronbach's test for tool one and its result was $\mathrm{R}=0.83$

\section{A pilot study}

A pilot study was carried out before starting of data collection including 20 mothers for the purpose to test the clarity, completeness, and to determine the time involvement. According to the results of the pilot study, the necessaries modifications were done. A pilot study was excluded from the studied sample. 


\section{Ethical considerations}

Research proposal was approved from ethical committee in the faculty of nursing, Assuit University. Oral consent was obtained from mothers who were willing to participate in the study, after explaining the nature and purpose of the study. Nature and the purpose of the study will be explained to all mothers. Confidentiality and anonymity was assured. Mothers had the right to withdraw from the study without any rational at any time.

\section{Field work}

The researcher interviewed each mothers individually at the outpatient clinic in Assuit Ophthalmology Hospital to obtain the necessary information. Interview questionnaire sheet was filled by the researcher herself and all the included questions was explained to mothers. The sheet required 15- 20 minutes to be filled, number of mothers / day was approximately 10 mothers. Data were collected during the period from the beginning of November until the end of December 2013.

\section{Limitations of the study}

1-Some mothers had shortage of time that impedes them from answering all the asked questions.

2-Overcrowding and noise in outpatient clinic related to a big number of children with conjunctivitis sometimes make communication difficult.

\section{Data analysis}

Data entry was done using compatible personal computer. The statistical analysis was done using statistical (SPSS) software version 20 and Excel for figures. The content of the tool was coded, tabulated and then analyzed. Data were presented using descriptive statistics in the form of frequencies and percentages for qualitative variables, means and stander deviations for quantitative variables. Variables were compared using chi-square test. Statistical significance was considered at $\mathrm{p}$. value $<0.05$. 


\section{Results}

Table (1): Distribution of mothers having children with conjunctivitis according to their personal characteristics at Assuit Ophthalmology Hospital.

\begin{tabular}{|c|c|c|}
\hline 1- Mothers' characteristics. & No. (200) & $\%$ \\
\hline \multicolumn{3}{|l|}{ Mothers' age in years } \\
\hline Range & \multicolumn{2}{|c|}{$17-45$ years } \\
\hline$<20$ & 9 & 4.5 \\
\hline $20<30$ & 121 & 60.5 \\
\hline $30<35$ & 33 & 16.5 \\
\hline $35+$ & 37 & 18.5 \\
\hline \multicolumn{3}{|l|}{ 2-Mothers' education } \\
\hline Illiterate & 77 & 38.5 \\
\hline Read and write & 17 & 8.5 \\
\hline Basic education & 34 & 17.0 \\
\hline Secondary education & 64 & 32.0 \\
\hline University education & 8 & 4.0 \\
\hline \multicolumn{3}{|l|}{ 3-Mothers' occupation } \\
\hline Employee & 12 & 6.0 \\
\hline House wife & 188 & 94.0 \\
\hline \multicolumn{3}{|l|}{ 4- Mothers' marital status } \\
\hline Married & 177 & 88.5 \\
\hline Divorced & 9 & 4.5 \\
\hline Widowed & 14 & 7 \\
\hline \multicolumn{3}{|l|}{ 5-Residence } \\
\hline Rural & 172 & 86.0 \\
\hline Urban & 28 & 14.0 \\
\hline \multicolumn{3}{|l|}{ 4-Crowding index level } \\
\hline $1-2$ persons per room & 81 & 40.5 \\
\hline$>2$ persons per room & 119 & 59.5 \\
\hline $\begin{array}{l}\text { 6- Positive history of maternal vaginitis during } p \\
\text { child birth? } \\
\text { Yes } \\
\text { No }\end{array}$ & $\begin{array}{c}111 \\
89\end{array}$ & $\begin{array}{l}55.5 \\
44.5\end{array}$ \\
\hline
\end{tabular}

Table (2): Distribution of the studied children with conjunctivitis according to their personal data at Assuit Ophthalmology Hospital.

\begin{tabular}{|l|c|c|}
\hline \multicolumn{1}{|c|}{ Child's Characteristics } & No. (200) & \% \\
\hline 1-Child's age in years & \multicolumn{2}{|c|}{$2 \pm 1.5$} \\
\hline$<1$ & 51 & 25.5 \\
\hline $1-<3$ & 82 & 41.0 \\
\hline $3-5$ & 67 & 48.0 \\
\hline Mean \pm SD & \multicolumn{2}{|c|}{} \\
\hline 2-Child's gender & 96 & 52.0 \\
\hline Males & 104 & 27.5 \\
\hline Females & \multicolumn{2}{|c|}{} \\
\hline 3- Birth order & 55 & 25.5 \\
\hline First & 51 & 17.0 \\
\hline Second & 34 & 12.0 \\
\hline Third & 24 & 18.0 \\
\hline Fourth & 36 & \\
\hline Fives \& & & \\
\hline
\end{tabular}


Table (3): Relation between mothers' total score of knowledge about conjunctivitis and their characteristics.

\begin{tabular}{|c|c|c|c|c|c|c|c|}
\hline \multirow{3}{*}{ Items } & \multicolumn{7}{|c|}{ Knowledge level } \\
\hline & \multicolumn{2}{|c|}{ Poor $(n=183)$} & \multicolumn{2}{|c|}{ Fair $(n=12)$} & \multicolumn{2}{|c|}{ Good $(n=5)$} & \multirow{2}{*}{ P. value } \\
\hline & No. & $\%$ & No. & $\%$ & No. & $\%$ & \\
\hline \multicolumn{8}{|l|}{ Mothers' age in years } \\
\hline Mean \pm SD & \multicolumn{2}{|c|}{$27.3 \pm 6.1$} & \multicolumn{2}{|c|}{$29.7 \pm 6.3$} & \multicolumn{2}{|c|}{$29.6 \pm 7.0$} & 0.331 \\
\hline$<20$ & 9 & 4.9 & 0 & 0.0 & 0 & 0.0 & \multirow{4}{*}{0.092} \\
\hline $20<30$ & 109 & 59.6 & 8 & 66.7 & 4 & 80.0 & \\
\hline $30<35$ & 32 & 17.5 & 1 & 8.3 & 0 & 0.0 & \\
\hline $35+$ & 33 & 18.0 & 3 & 25.0 & 1 & 20.0 & \\
\hline \multicolumn{8}{|l|}{ Mothers' education } \\
\hline Illiterate & 73 & 39.9 & 4 & 33.3 & 0 & 0.0 & \multirow{5}{*}{$0.001 * *$} \\
\hline Read and write & 17 & 9.3 & 0 & 0.0 & 0 & 0.0 & \\
\hline Basic education & 34 & 18.6 & 0 & 0.0 & 0 & 0.0 & \\
\hline Secondary education & 54 & 29.5 & 7 & 58.3 & 3 & 60.0 & \\
\hline University education & 5 & 2.7 & 1 & 8.3 & 2 & 40.0 & \\
\hline \multicolumn{8}{|l|}{ Mothers' occupation } \\
\hline Employee & 8 & 4.4 & 2 & 16.7 & 2 & 40.0 & \multirow{2}{*}{$0.001 * *$} \\
\hline House wife & 175 & 95.6 & 10 & 83.3 & 3 & 60.0 & \\
\hline \multicolumn{7}{|l|}{ Residence } & \multirow[b]{3}{*}{0.812} \\
\hline Rural & 157 & 85.8 & 12 & 100.0 & 3 & 60.0 & \\
\hline Urban & 26 & 14.2 & 0 & 0.0 & 2 & 40.0 & \\
\hline
\end{tabular}

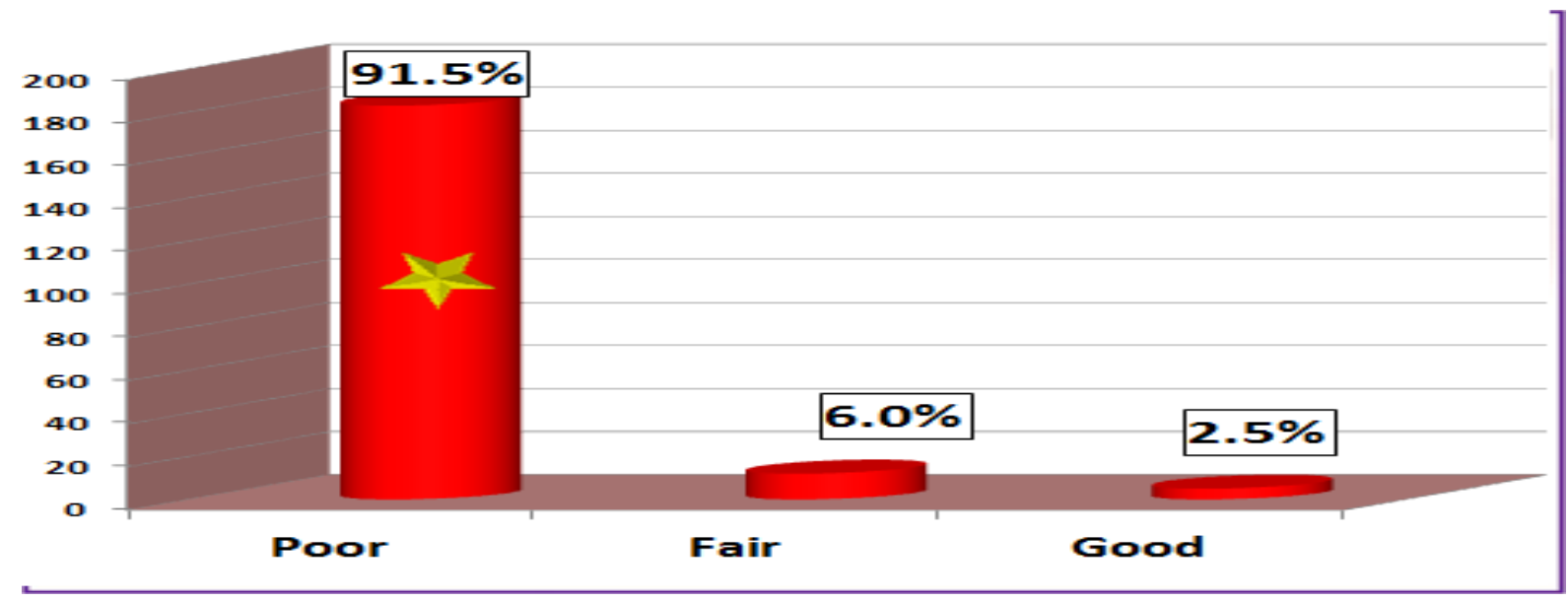

Fig (1): Scoring knowledge of the studied mothers about conjunctivitis.

Table (4): Total score of the studied mothers' practice to alleviate symptoms of conjunctivitis.

\begin{tabular}{|c|c|c|c|c|}
\hline \multirow{2}{*}{ Items } & \multicolumn{2}{|c|}{ Not done } & \multicolumn{2}{|c|}{ Done } \\
\hline & No. & $\%$ & No. & $\%$ \\
\hline Go to hospital or pharmacies to get medication & 83 & 41.5 & 117 & 58.5 \\
\hline Rinse the eye several times a day with water & 80 & 40.0 & 120 & 60.0 \\
\hline $\begin{array}{l}\text { Clean the eyelid margins and eyelashes gently and } \\
\text { repeatedly with a warm, moist cloth or cotton ball }\end{array}$ & 76 & 38.0 & 124 & 62.0 \\
\hline Cold compresses to cases of allergy conjunctivitis & 90 & 45.0 & 110 & 55.0 \\
\hline $\begin{array}{l}\text { Warm compress to cases of infectious conjunctivitis } \\
\text { (presence of discharge). }\end{array}$ & 85 & 42.5 & 115 & 57.5 \\
\hline
\end{tabular}

More than one answer was reported by the mother. 
Table (5): Total score of the studied mothers' practice to prevent infection of conjunctivitis.

\begin{tabular}{|l|c|c|c|c|}
\hline \multicolumn{1}{|c|}{ Items } & \multicolumn{2}{c|}{ Not done } & \multicolumn{2}{c|}{ Done } \\
\hline & No. & \% & No. & \% \\
\hline Wash your hands frequently, with soap and water & 164 & 82.0 & 36 & 18.0 \\
\hline $\begin{array}{l}\text { Be careful when you are using a compress. Because infections can } \\
\text { spread from eye to eye. }\end{array}$ & 160 & 80.0 & 40 & 20.0 \\
\hline $\begin{array}{l}\text { Use a separate compress for each eye and be sure to wash your } \\
\text { hands between applications }\end{array}$ & 158 & 79.0 & 42 & 21.0 \\
\hline $\begin{array}{l}\text { Start from the inside of the eye (closest to the nose) and wipe } \\
\text { outward }\end{array}$ & 162 & 81.0 & 38 & 19.0 \\
\hline $\begin{array}{l}\text { Use a different part of the compress for each wipe to minimize } \\
\text { cross-contamination }\end{array}$ & 163 & 81.5 & 37 & 18.5 \\
\hline $\begin{array}{l}\text { Do not share towels, washcloths, or pillowcases with anyone until } \\
\text { the symptoms are completely gone }\end{array}$ & 155 & 77.5 & 45 & 22.5 \\
\hline $\begin{array}{l}\text { Keep the child's hands away from his/her eyes as much as possible. } \\
\text { When he/she touches his/her infected eye, be sure to wash his/her } \\
\text { hands. }\end{array}$ & 161 & 80.5 & 39 & 19.5 \\
\hline $\begin{array}{l}\text { Change your pillowcase, washcloth and towel daily. Wash the dirty } \\
\text { ones in hot water }\end{array}$ & 159 & 79.5 & 41 & 20.5 \\
\hline \begin{tabular}{l} 
Do not share eye medicine (separated bottle to each one) \\
\hline Wear protective gloves when put eye medication to your child
\end{tabular} & 157 & 78.5 & 43 & 21.5 \\
\hline
\end{tabular}

More than one answer was reported by the mother

Table (6): Total score of the studied mothers' practice towards conjunctivitis.

\begin{tabular}{|l|c|c|}
\hline \multicolumn{2}{|c|}{ No. (200) } & \% \\
\hline Practice level & & 19.0 \\
\hline Good & 38 & 24.0 \\
\hline Fair & 48 & 57.0 \\
\hline Poor & 114 & \\
\hline
\end{tabular}

Table (7): Relation between mothers' total score of practice regarding conjunctivitis and their characteristics.

\begin{tabular}{|c|c|c|c|c|c|c|c|}
\hline \multirow{3}{*}{ Items } & \multicolumn{6}{|c|}{ Practice } & \multirow{3}{*}{ P. value } \\
\hline & \multicolumn{2}{|c|}{ Good } & \multicolumn{2}{|c|}{ Fair } & \multicolumn{2}{|c|}{ Poor } & \\
\hline & No. & $\%$ & No. & $\%$ & No. & $\%$ & \\
\hline \multicolumn{8}{|l|}{ Mother age } \\
\hline$<20$ years & 1 & 2.6 & 3 & 8.1 & 5 & 4.0 & \multirow{4}{*}{0.544} \\
\hline $20-30$ years & 21 & 55.3 & 17 & 45.9 & 83 & 66.4 & \\
\hline $30-35$ years & 6 & 15.8 & 7 & 18.9 & 20 & 16.0 & \\
\hline $35+$ years & 10 & 26.3 & 10 & 27.0 & 17 & 13.6 & \\
\hline \multicolumn{8}{|l|}{ Mother education } \\
\hline Illiterate & 8 & 21.1 & 9 & 28.1 & 60 & 46.2 & \multirow{5}{*}{$0.001 * *$} \\
\hline Read and write & 1 & 3.3 & 5 & 21.7 & 11 & 15.7 & \\
\hline Basic education & 3 & 8.3 & 6 & 30.0 & 25 & 40.3 & \\
\hline Secondary education & 20 & 31.3 & 10 & 24.4 & 34 & 20.4 & \\
\hline University education & 6 & 13.6 & 2 & 6.5 & 0 & 0.0 & \\
\hline \multicolumn{8}{|l|}{ Mother occupation } \\
\hline Employee & 7 & 18.4 & 2 & 6.9 & 3 & 2.3 & \multirow{2}{*}{$0.001 * *$} \\
\hline House wife & 31 & 81.6 & 27 & 93.1 & 130 & 97.7 & \\
\hline \multicolumn{8}{|l|}{ Residence } \\
\hline Rural & 32 & 84.2 & 40 & 83.3 & 100 & 87.7 & \multirow{2}{*}{0.724} \\
\hline Urban & 6 & 15.8 & 8 & 16.7 & 14 & 12.3 & \\
\hline
\end{tabular}


Table (8): Relation between mothers' total score of knowledge about conjunctivitis and their practice.

\begin{tabular}{|c|c|c|c|c|c|c|c|}
\hline \multirow{3}{*}{ Practice level } & \multicolumn{6}{|c|}{ Knowledge level } & \multirow{3}{*}{ P. value } \\
\hline & \multicolumn{2}{|c|}{ Poor $(n=183)$} & \multicolumn{2}{|c|}{ Fair $(n=12)$} & \multicolumn{2}{|c|}{ Good $(n=5)$} & \\
\hline & No. & $\%$ & No. & $\%$ & No. & $\%$ & \\
\hline Poor & 114 & 62.3 & $\overline{0}$ & 0.0 & $\overline{0}$ & 0.0 & \multirow{3}{*}{$0.001 * *$} \\
\hline Fair & 44 & 24.0 & 3 & 25.0 & 1 & 20.0 & \\
\hline Good & 25 & 13.7 & 9 & 75.0 & 4 & 80.0 & \\
\hline
\end{tabular}

Table (1): Distributes personal characteristics of mothers having children with conjunctivitis. It was observed that mothers' age ranged from 17 to 45 years, about three fifths of them $(60.5 \%)$ their age between $20-30$ years with a mean age of $27.5+6.1$ years. Regarding level of education, it was observed that slightly less than two fifths $(38.5 \%)$ of the studied mothers were illiterate, while only $(4.0 \%)$ of them were highly educated.

Concerning marital status, most of the studied mothers $(88.5 \%)$ were married. According to mothers' occupation, the vast majority (94\%) of them were housewives. As regards to residence, most of them $(86 \%)$ were living in rural areas. It was found that about three fifths of them (59.5\%) had crowding index $>2$ persons per room. Finally more than half of them $(55.5 \%)$ having vaginitis during pregnancy and child birth.

Table (2): Shows the personal characteristics of the studied children at Assuit ophthalmology hospital. It was observed that more than two fifths of them $(41.0 \%)$ were aged $1-<3$ years with a mean of age (2+1.5). 52.0\% of studied sample were females. Concerning to child's birth order, more than one quarter of them $(27.5 \%)$ were ranked as the first child in the family.

Table (3): Presents the relation between total knowledge of the studied mothers about conjunctivitis and their personal characteristics. It indicates highly statistical significant difference between the total knowledge of mothers about conjunctivitis and their education ( $\mathrm{p}$ value 0.001).Also it indicates highly statistical significant difference between the total knowledge of mothers about conjunctivitis and their occupation ( $p$ value 0.001).

Figure (1): Scoring knowledge of the studied mothers about conjunctivitis. This figure shows that the vast majority of the studied mothers $(91.5 \%)$ had poor knowledge about conjunctivitis.

Table (4): Shows the total score of the studied mothers' practice to alleviate symptoms of conjunctivitis. It shows that about three fifths of them go to hospital or pharmacies to get medication, rinse the eye several times a day with water and clean the eyelid margins and eyelashes gently and repeatedly with a warm, moist cloth or cotton ball. In addition more than half of them use practice of cold compresses to cases of allergic conjunctivitis and warm compresses to cases of infectious conjunctivitis.

Table (5): Presents the total score of the studied mothers' practice to prevent infection of conjunctivitis. It was revealed that most of them hadn't wash their hands frequently with soap and water, wasn't be careful when using a compress, wasn't use a separate compress for each eye, didn't be sure to wash their hands between applications, didn't use a different part of the compress for each wipe to minimize cross-contamination, didn't change their pillowcase, washcloth and towel daily and wash the dirty ones in hot water and didn't wear protective gloves when put eye medication to their children.

Table (6): Shows the total score of studied mothers' practice about conjunctivitis. It shows that more than half of them $(57.0 \%)$ had poor practice.

Table (7): Presents the relation between mothers' total score of practice regarding conjunctivitis and their characteristics. It was observed that there were statistical significant difference between mothers' education and their practice regarding conjunctivitis ( $\mathrm{P}$ value 0.001 ). It was found that most of mothers with good practice regarding conjunctivitis $(75 \%)$ were among those with university education, also most of the mothers having poor practice $(77.9 \%)$ was among the illiterate mothers. Also there was statistical significant difference between mothers' occupation and their practice regarding conjunctivitis ( $\mathrm{P}$ value 0.001 ). It was found that mothers with good practice regarding conjunctivitis (16.5\%) was among the working mothers, while most of them with poor practice $(69.1 \%)$ was among the housewives mothers. Table (8): Presents the relation between mothers' total score of knowledge about conjunctivitis and their practice. It indicates highly statistical difference between mothers' knowledge and practice. Also most of mothers have poor knowledge and poor practice.

\section{Discussion}

Acute conjunctivitis is the most common eye disorder in young children and is the most frequent ophthalmologic complaint seen in the pediatric 
emergency department. Allergic conjunctivitis is the most frequently reported childhood eye disease, which is the second most common cause of eye diseases. Ocular infections are preventable but challenging causes of blindness, particularly in children given the number of blind years involved. (Sherwin et al., (2010)

This study aimed to assess knowledge \& practice of mothers having children suffering from conjunctivitis. In the present study more than two fifths of children $(41.0 \%)$, their age ranged from one to less than 3 years with mean $+\mathrm{SD}$ of age $(2 \pm 1.5)$. This result agree with (Ricci \& Kyle, 2009). "Infectious conjunctivitis is very contagious, so epidemics are common, particular in young children". Concerning to the child's gender, the results of present study revealed that $52.0 \%$ were females and $48.0 \%$ were males. This result is in an agreement with that reported by Abokyi et al.,( 2012), the study Epidemiological profile and pharmacological management of allergic conjunctivitis , A study in Ghana who reported similar results $(38.2 \%)$ males and $(61.8 \%)$ females. On other hand these results disagreed with Raja Kumar Pasam \& UdayKumar, (2008) A Study of Spectrum of Childhood Eye Diseases, At a Tertiary Care Hospital in South India who noted that no gender differences were observed. This disagreement may because males were particularly important to their parent so they gained more attention and protection than female especially in rural areas.

According to residence, the present study showed that conjunctivitis more prevalent among rural $(86 \%)$ than urban $(14 \%)$. It may be explained by poor hygienic environment, dust area, open area, flies, lower socioeconomic status and mothers' low educational level. These factors are common in rural area. In addition to young of age children ( $>5$ years) who can't take care of their own cleanliness. This finding was in the same line with Rashwan and Mohamed, (1992); Heather \& Zar, (2005). Trachoma infection among primary school children in Kena Governorate, Egypt, The prevalence of chlamydial conjunctivitis among those with unclean faces was three times more likely to have clinical chlamydial conjunctivitis or ocular C. trachomatis infection.

On addition the present study revealed that about three fifths of children with conjunctivitis live in crowding houses, overcrowding could increase rate of infection spread.

According to the personal characteristics of the studied mothers the present study reveals that mothers' age ranged from 17:45 years, with a mean age of $27.5+6.1$ years. More than three fifths of them were young mothers (20:30 years).
Regarding level of education, it was observed that slightly less than two fifths $(38.5 \%)$ of the studied mothers were illiterate, while only $(4.0 \%)$ of them were highly educated. In my opinion illiteracy mothers usually found difficulty to understand the nature of disease and to apply a new management strategy of treatment. Education greatly strengthens the women to perform their vital roles in caring of their children and creating a healthy environment.

According to mothers' occupation the vast majority $(94 \%)$ of them were housewives this due to unemployed mothers makes them not interesting in increasing their knowledge and living traditional day activity without novation. And employed mothers interact with educated people that having knowledge and experience this increases their knowledge and experience.

In addition the present study shows more than half of studied mothers had vaginitis during pregnancy and child birth. This agreed with Kara et al., (2014) who noted that $\mathrm{C}$. trachomatis infection of the newborn is acquired from infected birth canal of the mother. Therefore, C. trachomatis infection in the infants is an indicator of genital tract infection in their mothers. Studies have shown that $18-50 \%$ infants born to culture positive mothers develop conjunctivitis. As C. trachomatis is now considered the most common cause of sexually transmitted infections in the world.

The present study revealed that there was statistical significant difference between mothers' knowledge regarding conjunctivitis and their education. It shows that the vast majority of them $(91.0 \%)$ have poor knowledge regarding conjunctivitis. In my opinion this related to illiteracy mothers usually found difficulty to understand the nature of disease and to apply anew management strategies of treatment. Education greatly strengthens the women to perform their vital roles in caring of their children and creating a healthy environment and unemployment of mothers make them not interesting in increasing their knowledge and living traditional day activity without novation.

The present study results according to the total score of studied mothers' practice about conjunctivitis. It shows that the majority of them $(81.0 \%)$ had poor practice.

With regarding to ask the study sample about their practice to alleviate symptoms of conjunctivitis to their children it shows that more than half of them have good knowledge about practice to alleviate symptoms but I'm don't know if they practice them or not because they may not know the importance of this practice or only depending on medication.

As regard to asking the study sample about their practices to prevent spread of conjunctivitis. It was noted that the majority of them $(80.5 \%)$ didn't know 
or perform practices to prevent infection of conjunctivitis.

According to relation between mother's education, their practice and knowledge about conjunctivitis the present study noted that there is highest significance between mother's education, their practice and knowledge it recorded that the highest percentage $(25 \%)$ of mothers with good knowledge about conjunctivitis was among those with university education, while most of mothers with poor knowledge $(94.8 \%)$ was among the illiterate mothers. Also it was found that the highest percentage of mothers with good practice regarding conjunctivitis (75\%) was among those with university education, while the highest percentage of mothers with poor practice $(77.9 \%)$ was among the illiterate mothers. And there are no significance relations between mothers' knowledge \& practice and mothers' age \& residence.

As regarding to relation between mothers' occupation and their knowledge \& practice regarding early childhood conjunctivitis the present study noted that there is highest significance between mothers' occupation and their knowledge \&practice it recorded that the highest percentage $(16.7 \%)$ of mothers with good knowledge about conjunctivitis was among employed mothers, while the highest percentage of mothers with no knowledge $(93.1 \%)$ was among unemployed mothers. Also it was found that the highest percentage of mothers with good practice regarding conjunctivitis $(58.3 \%)$ was among employed mothers, while the highest percentage of mothers with poor practice $(69.1 \%)$ was among unemployed mothers.

\section{Conclusion}

Based on the results of the present study, the vast majority of mothers had poor knowledge and practice regarding conjunctivitis. There were significant relations between mothers' education, working condition, their knowledge and practice regarding pediatric conjunctivitis at Assuit Ophthalmology Hospital.

\section{Recommendations}

1. Health classes about management and prevention of pediatric conjunctivitis for mothers should be held at Assuit ophthalmology hospital.

2. There is a need to have more stress by nurses on the principles of good hygiene and clean newborn care practices by mother and attendants in all pediatrics centers.

3. Educational program toward pediatric conjunctivitis should be established for community health nurses at rural health units and ophthalmology hospital.
4. A well-planned health education program about pediatric conjunctivitis into the curriculum at preparatory, secondary school and university levels.

5. A written pamphlet or booklet containing information about pediatric conjunctivitis as (symptoms, causes, mode of transmission and how to prevent it, treatment, and how to care of infected child....etc) and keep copies in clinics and department of ophthalmology and give educated mothers copies to use that when necessary.

6. Follow up sheet to every child has conjunctivitis frequently to identify causes of his recurrent infection and prevent it before complications that are avoidable before occurring.

7. Based in the results of this study which revealed that mothers had poor knowledge and poor practice regarding conjunctivitis this lead to progressive booklet contained simple information about pediatric conjunctivitis as (symptoms, causes, mode of transmission and how to prevent it, treatment, and how to care of infected child...etc) was developed and used in giving health education during the study to improve mothers knowledge and practice regarding conjunctivitis.

\section{References}

1. Abokyi S., Koffuor M., Ntodie, S., Kyei, L., (2012): Epidemiological profile and pharmacological management of allergic conjunctivitis: A study in Ghana, International Journal of pharmaceutical and biomedical research, Received: 04 Oct 2012 / Revised: 09 Oct 2012 / Accepted: 10 Oct 2012 / Online publication: 13 Oct 2012; 3(4) : 195 - 201

2. American Academy of Pediatrics, (2012): School Health. In: Pickering LK., ed. Red Book, Report of the Committee on Infectious Diseases. $29^{\text {th }}$ ed. Elk Grove Village, IL: American Academy of Pediatrics: 222. Bang AT, Bang RA, Baitule SB, Reddy MH.

3. American Academy of Pediatrics, (2010): Managing Infectious Diseases in Childcare and Schools. Elk Grove Village, IL: American Academy of Pediatrics; for a general guide on caring for young children, refer to American Academy of Pediatrics. Caring for Your Baby and Young Child: Birth to Age 5. Shelov SP, Hannemann RE, eds. 4th ed. New York, NY: Bantam Books; 2004.

4. Brunner L., \& suddarth D., (2008): Textbook of Medical -surgical nursing $11^{\text {th }}$ ed., volum2, 12307 by lippin cott willams \&wikins chapter 58, page 2076:2079. 
5. Centers for Disease Control and Prevention (CDC), (2014): Pink Eye: Usually Mild and Easy to Treat available at http://www.cdc.gov/ncird/

6. Denniston A., (2008): Murry pi.oxford Handbook of ophothalmology (oup).

7. Donahue S., Khoury J., \& Kowalski RP, (1996): Common ocular infections. A prescriber's guide. Drugs; 52(4):526-40.

8. Heather J., \& Zar, (2005): Neonatal chlamydial infections. Pediatric Drugs ;7(2):103-110. http://www.dh.sa. gov.au/pehs/You've-got-what/handwashing. htm>

http://www.dh.sa.gov. au/pehs/ You'vegotwhat/stop-disease-spread.htm> http://www.dh.sa.gov.au/pehs/ You've-gotwhat/exclusion-from-school. htm>

9. Kara, L., Mattina, Thompson \& Lisa, (2014): Pediatric conjunctivitis, Disease-aMonth; 60 (6): 231- 238.

10. Navachetan E., (2011): A study to assess the knowledge and practice regarding over the counter medication for conjunctivitis of children among parents of under five children residing at selected rural areas of tumkur, with a view to develop information booklet. Bangalore: RGUHS; 2(3):Pp. 17-21.

11. RajaKumar Pasam \& UdayKumar, (2008): A Study of Spectrum of Childhood Eye Diseases, At A Tertiary Care Hospital in South India, Ijsr - international journal of scientific research, may 2014; 3 (5 ): 439- 442

12. Rashwan A., \& Mohamed S., (1992): Trachoma infection among primary school children in Al-Koom Al-Ahmar, Kena Governorate, Egypt. Egypt J Comm Med, 10 (1): 45-52.

13. Ricci S., \& Kyle T., (2009): Conjunctivitis, maternal -child nursing, china, 12282,ch,38,p,1192:1196.

14. Rod S., Cinnamon Vanputte, Jennifer Regan \& Andrew Russo, (2011): Anatomy of the eye, Anatomy and physiology, 9 th ed., 2164, United States of America, ch 15, page 517:524.

15. Royal College of Nursing, (2009): The nature scope and value of ophthalmic nursing, The RCN represents nurses and nursing, promotes excellence in practice and shapes health policies, third edition RCN Online www.ren.org.uk RCN Direct www.rcn.org.uk/direct 1-906636-15-8.

16. Sherwin J., et al., (2010): A controlled trial of povidone-iodine to treat infectious conjunctivitis in children.Am J Oph, 2002; 134(5): 681-88. 